\title{
Thoracic surgery in Estonia
}

\author{
Tanel Laisaar ${ }^{1,2}$ \\ ${ }^{1}$ Department of Thoracic Surgery and Lung Transplantation, Lung Clinic, Tartu University Hospital, Tartu, Estonia; ${ }^{2}$ Lung Clinic, Medical Faculty, \\ Tartu University, Tartu, Estonia \\ Correspondence to: Tanel Laisaar. Department of Thoracic Surgery and Lung Transplantation, Tartu University Hospital, Puusepa 8, 50404 Tartu, \\ Estonia. Email: tanel.laisaar@kliinikum.ee.
}

\begin{abstract}
Estonia, a small Northern European country with the population of 1.3 million, has two centres of thoracic surgery, both established in 1960s. One is in the capital Tallinn, and another in the university town Tartu. Both departments cover the full spectrum of thoracic surgery, apart from oesophageal cancer surgery, yet including paediatric operations and chest trauma management. However, the focus is on lung cancer surgery. Currently, the proportion of lung cancer cases treated surgically is $20 \%$ in Estonia. Between 2000 and 2015 the proportion of lobectomies increased from $53 \%$ to $76 \%$, while pneumonectomies decreased from $28 \%$ to $8 \%$. Although the absolute number of lung cancer operations in Estonia is small, upon need complex and extended resections are performed. In the last decades a considerable survival gain of lung cancer patients has been observed. Minimally invasive surgery is widely used since its implementation in 1995, with the list of indications constantly evolving. In 2005, first video-assisted thoracoscopic (VATS) thymectomy and lobectomy were performed. VATS as surgical access in lung cancer operations exceeded thoracotomy in 2015 and is currently considered in all cases. In 2018, the first uniportal VATS sleevelobectomy was performed. The lung transplant program is functioning together with other solid organ transplant programs only at the Tartu University Hospital. Up to now, 33 lung transplantations have been performed, including lobar transplantations, a paediatric case, a few urgent cases for patients on extracorporeal membrane oxygenation (ECMO), and two re-transplantations. General thoracic surgery is a separate monospeciality in Estonia with an independent 5-year residency program, which is arranged by the Medical Faculty of University of Tartu. In last years, thoracic surgery related research in Estonia has mainly focused on lung cancer detection and management. Currently, a national lung cancer screening program feasibility study is being led by thoracic surgeons.
\end{abstract}

Keywords: Thoracic surgery; Estonia; lung cancer

Submitted Jul 11, 2021. Accepted for publication Oct 19, 2021.

doi: $10.21037 /$ jtd-21-1146

View this article at: https://dx.doi.org/10.21037/jtd-21-1146

\section{Estonia}

Estonia is a relatively small Northern European country with a population of only 1.3 million and a territory of 45 thousand square kilometres. The capital Tallinn is the largest city, where together with the suburbs, lives almost half of the country's population. The second largest city is the university town Tartu with 100,000 inhabitants. The only medical faculty in Estonia is at the University of Tartu (established in 1632).

Estonia has solidary health insurance. Funding comes from $13 \%$ of the social tax, payable form gross salary. In addition to people paying the taxes, i.e., those working, the insurance also covers children, students, seniors, and some other population groups. Altogether, 93.6\% of Estonian population is covered with health insurance (1).

In past years, in Estonia the leading causes of death have been diseases of the circulatory system, followed by malignant neoplasms, and injuries and poisoning. In January 2021, during the second wave of the COVID-19 pandemic, respiratory diseases rose to the third place-out of the 199 deaths caused by respiratory diseases, 154 were due to 
COVID-19, which accounted for $10 \%$ of all the deaths in this month in Estonia $(2,3)$.

In 2018, according to the Estonian Cancer Registry 8,783 new cases of cancer were diagnosed. The most common was non-melanoma skin cancer, followed by prostate, colorectal and lung cancer. Lung cancer is the second most common cancer among males and fifth among females (4).

According to a recent study $17.9 \%$ of Estonian adults (25.7\% males and $12.6 \%$ females) are daily smokers, and $8.2 \%$ are occasional smokers (5). Smoking prevalence is constantly decreasing among both males and females.

In 2020, the life expectancy in Estonia was 74.4 years for males and 82.8 years for females (6).

\section{History of thoracic surgery in Estonia}

In Estonia, general thoracic surgery is a separate monospeciality. It started to develop from the first thoracic operations, which were performed at the beginning of 20th century mostly due to tuberculosis. During the second world war thoracic surgical activity was low, but thereafter slowly recovered. During the 1950 s, in addition to thoracoplasty and several minor operations for tuberculosis, also first lung resections were performed. Thoracic surgery concentrated into two cities-Tallinn and Tartu.

A specialized department for thoracic surgery was established in Tartu Tuberculosis Hospital in 1965, and in Tallinn Oncology Hospital in 1967. At the same time, tracheal intubation and general anaesthesia were introduced in Estonia, which allowed to expand the indications for surgery. However, the number of lung resections performed due to cancer exceeded the resections due to tuberculosis only by the middle of the seventies.

Currently in 2021 there are also only two departments of thoracic surgery in Estonia, where all thoracic operations are performed: the Department of Thoracic Surgery and Lung Transplantation in Tartu University Hospital with 14 beds and 4 specialized surgeons (in Tartu), and the department of thoracic surgery in North-Estonia Medical Centre with 14 beds and 5 surgeons (in Tallinn). In past years, the annual number of operations performed in these departments has been around 450 and 500, respectively. The main indication for surgery is lung cancer, which accounts approximately one third of thoracic operations.

The Estonian Society of Thoracic Surgery, established in 2006, incorporates all Estonian thoracic surgeons and a few other related specialists. The society has annual meetings and represents its members in any interaction with the Ministry of Social Affairs and the Estonian Health Insurance Fund. The society has had 2 presidents-Tanel Laisaar (a founder and the $1^{\text {st }}$ president) and Ingemar Almre (the current president).

\section{Scope of general thoracic surgery in Estonia}

According to the definition of the European Society of Thoracic Surgery general thoracic surgery includes diagnosis and management of congenital or acquired diseases of the chest, including diseases of the chest wall, pleura, lungs, airways, mediastinum, diaphragm and oesophagus (7). Both departments of thoracic surgery in Estonia correspond well to the definition and cover the full spectrum of thoracic surgery, apart from oesophageal surgery. Oesophageal cancer operations have been traditionally performed by general oncological surgeons in Estonia. However, some benign oesophageal diseases and complicated cases of oesophageal perforation are handled by thoracic surgeons.

General thoracic surgeons also operate on paediatric patients, including patients with congenital lung malformations, pleural diseases, and chest deformities. Minimally invasive repair of pectus excavatum is performed in cooperation with paediatric surgeons. For surgical management of rare congenital and complex cases of laryngotracheal diseases, since 2018 the North Estonia Medical Centre and Tallinn Children Hospital have cooperated with the Airway Unit of the Service of Otorhinolaryngology and Head and Neck Surgery at Lausanne University Hospital in Switzerland.

The majority of isolated chest trauma cases are treated in thoracic surgery departments. In both centres, one thoracic surgeon is on call for $24 / 7$ in case there is a need for an emergency thoracotomy. Thoracoscopic approach has been also introduced in trauma setting when applicable. Over past years, the use of chest wall stabilization with MatrixRIB ${ }^{\circledR}$ Fixation System (DePuy Synthes) has increased.

Besides major surgical operations, thoracic surgeons take part in preoperative diagnostic workup of patients by taking biopsies, performing bronchoscopies, including endoscopic ultrasound (EBUS), and occasionally rigid bronchoscopy. Although wider use of EBUS has mostly eliminated the need for a mediastinoscopy, it is still in the armamentarium of thoracic surgery. The preoperative management of surgical patients (incl. lung cancer cases) is carried out mostly in the two regional hospitals, in close collaboration with pneumologists. Positron-emission tomography (PET) 
is increasingly, but not yet routinely, used in preoperative workup of lung cancer patients. Thoracic surgeons also participate in multidisciplinary discussions on the treatment of various diseases of the chest. A thoracic surgeon is an obligatory team member when decisions on lung cancer patients' management are made.

\section{Lung cancer surgery}

In Estonia, approximately 800 new lung cancer cases are diagnosed each year. It is mandatory to report all cancer cases to the Estonian Cancer Registry, which has reliable incidence data since 1968. Besides that, a few years ago, quality registries were implemented in both the Estonian thoracic surgery departments, collecting detailed data about surgically treated lung cancer cases.

The full spectrum of treatment modalities is available for cancer patients in Estonia, including targeted treatment and immunotherapy for advanced stage cancer. For early stage lung cancer, surgical treatment is the preferred option, when lung function and general status of the patient allow radical lung resection. An anatomical lung resection, either segmentectomy or lobectomy together with radical lymphadenectomy, is the standard of care. Segmentectomy is used in case of peripheral small tumors even in patients with normal lung function, especially in cases where upper segment of the lower lobe or left upper lobe (either upper trisegmentectomy or lingulectomy can be performed) is involved. Bronchial sleeve resection is attempted whenever possible to avoid pneumonectomy.

Although the number of lung cancer cases in Estonia has been quite stable over the last decades, the number of lung cancer operations has increased steadily (8). Considerable survival gain of lung cancer patients have been observed during the same time, which can largely be attributed to growing proportion of surgically treated patients, emphasizing the central role of surgery in the treatment of all major histologic types of lung cancer (8).

Between the years 2000 and 2015, the proportion of lung cancer cases treated surgically increased from $14 \%$ to $20 \%$ (9). The percentage of lobectomies increased from $53 \%$ to $76 \%$, while pneumonectomies decreased from $28 \%$ to $8 \%$. The mean age of patients increased from 63 to 67 years, and the proportion of women from $18 \%$ to $31 \%$ (10). Reasons behind these trends are probably better diagnostics, including wider availability of chest computed tomography (CT) scans, and increased awareness of lung cancer.

In 2020, altogether 239 lung cancer operations were performed in Estonia, with 170 being (bi)lobectomies, and $16(9.4 \%)$ of the lobectomies being sleeve lobectomies. Two hundred and twenty-five (94.1\%) of the patients underwent a complete $\mathrm{R} 0$ resection (unpublished data).

Use of video-assisted thoracoscopic surgery (VATS) is currently considered in all lung cancer surgical treatment cases, and routinely used in stage I and II lung cancer operations. In Estonia, the first VATS lobectomy for lung cancer was performed in 2006, and uniportal access for major anatomical lung resections was implemented in 2015. By 2015, as surgical access in lung cancer operations, the VATS approach had exceeded thoracotomy (9). First uniportal VATS sleeve-lobectomy was performed in 2018. In 2020, altogether 170 (71.1\%) of lung cancer operations were attempted by VATS, and the conversion rate to thoracotomy was $8.9 \%$. The median hospital stay after lung cancer operations was 6 days (5 days after VATS and 9 days after thoracotomy), and 30-day postoperative mortality was $0.8 \%$ (unpublished data).

Although the absolute number of lung cancer operations in Estonia is small, upon need complex and extended resections are performed. Lung cancer invading the pericardium or diaphragm, and vascular involvement (including aorta and atrium in highly selected cases) are not considered contraindications for surgical treatment, and in some cases even the thoracoscopic approach is used. In carefully selected patients (e.g., with superior sulcus tumor, a cancer with sternal or vertebral invasion) extensive chest wall resection and reconstruction, and pneumonectomy with carinal resection have been successfully performed (11).

Regular follow-up using CT and bronchoscopy (in case of sleeve resections) for up to five years is recommended for all surgically treated lung cancer patients.

Besides lung cancer surgery, also operations for lung metastases, mediastinal tumors, and the rare cases of pleural mesothelioma are performed by thoracic surgeons.

\section{Minimally invasive thoracic surgery}

First VATS operations in Estonia were performed in Tartu University Hospital in 1995. Over the years, the spectrum of indications for VATS has widened steadily. Initially simple pleural procedures (pleurodesis, pleurectomy, etc.), minor lung resections and biopsies, sympathectomies, etc. were performed by VATS. Gradually more complex operations were introduced, using the VATS approach in patients with pleural empyema and mediastinitis (12). In 2005 , the first VATS thymectomy and lobectomy were 


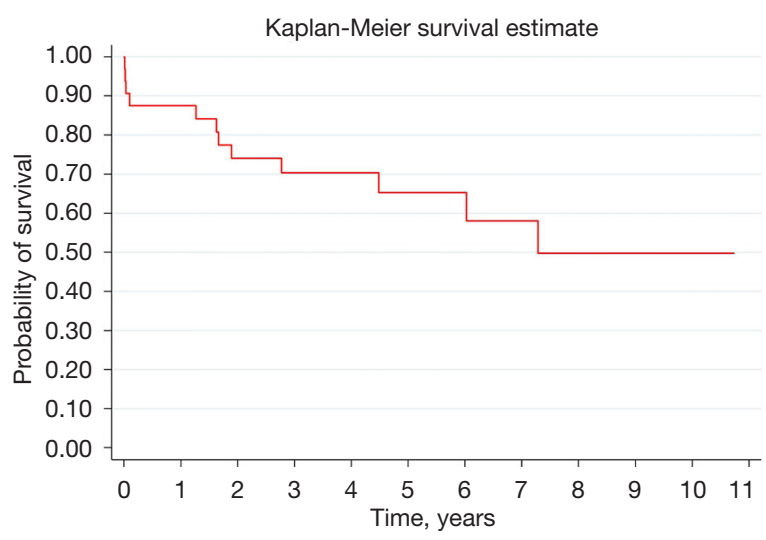

Figure 1 Kaplan-Meier survival estimate on 33 lung transplant patients in Estonia between 2010-2021.

performed in the Tartu University Hospital. Currently, VATS is widely used for a broad range of indications in both the Estonian thoracic surgery centres. Complex cases like sleeve lobectomy, completion pneumonectomy, extended cancer resections have also been occasionally performed by VATS. The wide use and early introduction of VATS for many indications have been possible due to the availability of modern equipment, including high-quality surgical instruments and staplers.

\section{Lung transplantation}

All solid organ transplantations in Estonia are performed in Tartu University Hospital. The lung transplant program was initiated as the third transplant program after the already existing kidney and liver transplant programs. The preparations were carried on in close cooperation with Professor Walter Klepetko and his co-workers from the Vienna Lung Transplant program. The first Estonian patient was transplanted in Vienna in 2009. The first lung transplantation in Estonia was performed in 2010-the patient underwent bilateral lobar transplantation. Both these patients are still alive, although the first one underwent retransplantation a few years later in Estonia.

Since 2018, Estonia is a member of Scandiatransplant (the organ exchange organization uniting transplant centres form Finland, Sweden, Norway, Denmark, Island and Estonia), and therefore close cooperation and donor organ exchange has been established with Scandinavian countries.

Up to June 2021, altogether 33 lung transplantations (31 bilateral and 2 single lung transplantations) have been performed in Estonia. The most common indications have been COPD and emphysema, but also pulmonary fibrosis, pulmonary hypertension, cystic fibrosis, ARDS, and post-COVID lung damage. Two re-transplantations for chronic lung allograft dysfunction were performed and one paediatric patient has been transplanted. Four urgent transplantations have been performed for patients on preoperative extracorporeal membrane oxygenation (ECMO). In addition, intra- and postoperative ECMO support has been used in several other cases. Even though patients with several comorbidities and relative contraindications have been accepted for transplantation, postoperative survival has been comparable to the international median from the very beginning of the transplant program (13). The overall five-year survival of lung transplant patients is $65 \%$, which slightly exceeds current international results according to the International Society of Heart and Lung Transplantation database (Figure 1) (14).

\section{Specialization and training in thoracic surgery}

Training in general thoracic surgery is arranged by the Faculty of Medicine at the University of Tartu. A part-time associate professor is responsible for arranging thoracic surgical education for medical students and postgraduate specialists. Each year around 150 new doctors graduate from the Faculty of Medicine, University of Tartu. A prerequisite for entering postgraduate medical training (residency) in Estonia is the degree in medicine, equivalent to the medical programme at the University of Tartu; proficiency in the Estonian language; a working or permanent living permit for foreign residents, and a document which certifies registration as a physician at the Estonian Health Board. The candidate must pass an entrance exam. Due to the small number of thoracic surgeons needed in Estonia, new residency positions are not opened every year.

Duration of the residency program in general thoracic surgery is 5 years, with the first 2 years as a common trunk (similar with other surgical disciplines) and the last 3 years specialization in general thoracic surgery. The specialization part includes, in addition to general thoracic surgery, also a few months of training in cardiac surgery, oncology and pneumology (incl. training in bronchoscopy). The general thoracic surgery residency program is independent from the general surgery and the cardiac and vascular surgery training programs.

To graduate the residency program, the candidate must fully complete the theoretical and practical training, have 
performed independently at least 300 operations (incl. 200 general thoracic operations) and pass the final exam. The residency program is financed by the state through the Estonian Health Insurance Fund.

Regular accreditation of medical specialists is not mandatory in Estonia; however accreditation is provided by several medical societies for the respective speciality. Surgeons (including thoracic surgeons) are accredited by the Estonian Association of Surgeons.

\section{Research in thoracic surgery}

Research has always been an integral part of thoracic surgery in Estonia. Already more than 80 years ago first papers were published in the Estonian medical journal "Eesti Arst" ("The Estonian Doctor"), at the time focusing on surgery for tuberculosis (15). Research topics like treatment of pleural empyema, solitary pulmonary nodule and lung cancer have been attractive over time, and the results have been published both internationally and nationally. At one point in time, a paper by Estonian researchers has even been the most downloaded publication of the journal "Interactive Cardiovascular and Thoracic Surgery" (16,17).

During last years, thoracic surgery related research in Estonia has mainly focused on lung cancer detection and management. In last 5 years, 17 papers by Estonian thoracic surgeons have been published in international peerreviewed medical journals. Currently in 2021, a national lung cancer screening program feasibility study is being led by one of the thoracic surgeons from the Tartu University Hospital.

Estonian thoracic surgeons have also participated in several international multicentre research projects, including large lung cancer clinical trials like MAGRIT, PRAME $(18,19)$, and are currently involved in the ongoing clinical trial KEYNOTE 671.

\section{Future perspectives of thoracic surgery}

According to the Estonian development plans of the health system thoracic surgical services will continue to be offered in the current two centres (regional hospitals).

Robotic surgery is not available in Estonia, as manufacturers have not been keen on entering such a small market. Still, minimally invasive surgery is the favoured area of development. Also, the internationally trendy awake and tubeless operations, and enhanced recovery after surgery programmes are under evaluation in Estonia. In addition, thoracic surgeons will continue to lead the lung cancer screening program implementation activities.

\section{Summary}

Estonia is a small country with only two centres of thoracic surgery (in Tallinn and Tartu), where all the country's thoracic operations are concentrated in. The full spectrum of general thoracic operations, including minimally invasive operations, are performed in both the centres, with focus on lung cancer surgery. As an exception, the lung transplant program is only running in Tartu University Hospital, where all solid organ transplantations are performed.

In Estonia, thoracic surgery is a monospeciality, independent from cardiac and vascular surgery. Specialization in thoracic surgery (the residency) lasts 5 years, and the training program is coordinated by the University of Tartu.

\section{Acknowledgments}

The author would like to acknowledge the head of the Department of Thoracic Surgery in North Estonia Medical Centre dr Tõnu Vanakesa for providing data about lung cancer operations in Tallinn, and his valuable comments.

Funding: None.

\section{Footnote}

Provenance and Peer Review: This article was commissioned by the Guest Editor (Alan D. L. Sihoe) for the series "Thoracic Surgery Worldwide" published in Fournal of Thoracic Disease. The article has undergone external peer review.

Peer Review File: Available at https://jtd.amegroups.com/ article/view/10.21037/jtd-21-1146/prf

Conflicts of Interest: The author has completed the ICMJE uniform disclosure form (available at https://jtd.amegroups. com/article/view/10.21037/jtd-21-1146/coif). The series "Thoracic Surgery Worldwide" was commissioned by the editorial office without any funding or sponsorship. The author has no other conflicts of interest to declare.

Ethical Statement: The author is accountable for all aspects of the work in ensuring that questions related to the accuracy or integrity of any part of the work are 
appropriately investigated and resolved.

Open Access Statement: This is an Open Access article distributed in accordance with the Creative Commons Attribution-NonCommercial-NoDerivs 4.0 International License (CC BY-NC-ND 4.0), which permits the noncommercial replication and distribution of the article with the strict proviso that no changes or edits are made and the original work is properly cited (including links to both the formal publication through the relevant DOI and the license). See: https://creativecommons.org/licenses/by-nc-nd/4.0/.

\section{References}

1. Available online: https://en.tai.ee/en/health-data/ health-statistics-and-health-research-database/latestupdates/5010-93-6-percent-of-the-estonian-population-isinsured, accessed 29.06.2021.

2. Available online: https://en.tai.ee/en/health-data/ health-statistics-and-health-research-database/latestupdates/4997-circulatory-system-diseases-were-the-causeof-half-of-the-deaths, accessed 29.06.2021.

3. Available online: https://en.tai.ee/en/health-data/ health-statistics-and-health-research-database/latestupdates/5026-in-january-the-coronavirus-caused-a-tenthof-deaths-in-estonia, accessed 29.06.2021.

4. Available online: https://www.tai.ee/et/uudised/2018aastal-diagnoositi-8783-vahi-esmasjuhtu, accessed 29.06.2021.

5. Reile R, Veideman T. Eesti täiskasvanud rahvastiku tervisekäitumise uuring [In English: The national population-based survey of the health behaviour of adults in Estonia 2020]. National Institute for Health Development; 2021.

6. Available online: https://www.stat.ee/en/find-statistics/ statistics-theme/well-being/health/life-expectancy, accessed 08.09.2021.

7. Brunelli A, Falcoz PE, D'Amico T, et al. European guidelines on structure and qualification of general thoracic surgery. Eur J Cardiothorac Surg 2014;45:779-86.

8. Innos K, Oselin K, Laisaar T, et al. Patterns of survival and surgical treatment in lung cancer patients in Estonia by histologic type and stage, 1996-2016. Acta Oncol 2019;58:1549-56.

9. Põdra G. Data quality of primary lung cancer cases that underwent radical surgery in the Estonian Cancer Registry. Masters thesis, University of Tartu; 2018.

10. Lelebina $\mathrm{L}$. Changes in surgical treatment of lung cancer in Estonia in 2000-2015. Masters thesis, University of Tartu; 2018.

11. Aim A, Almre I, Vanakesa T. Combined approach using uniportal video-assisted thoracoscopic surgery in left tracheal sleeve pneumonectomy. J Thorac Dis 2018;10:E584-6.

12. Laisaar T. Video-assisted thoracoscopic surgery in the management of acute purulent mediastinitis and pleural empyema. Thorac Cardiovasc Surg 1998;46:51-4.

13. Laisaar T, Savisaar M, Parm P, et al. Initial experience with lung transplantation in Estonia. Transplant Proc 2013;45:1204-8.

14. Chambers DC, Yusen RD, Cherikh WS, et al. The Registry of the International Society for Heart and Lung Transplantation: Thirty-fourth Adult Lung And HeartLung Transplantation Report-2017; Focus Theme: Allograft ischemic time. J Heart Lung Transplant 2017;36:1047-59.

15. Thomson F. Modifitseeritud torakoplastikast kopsutuberkuloosi ravimisel. Eesti Arst 1939;5:309-37.

16. von Segesser LK, Beyersdorf F. Ten years of Interactive CardioVascular and Thoracic Surgery. Interact Cardiovasc Thorac Surg 2012;15:571-3.

17. Laisaar T, Palmiste V, Vooder T, et al. Life expectancy of patients with malignant pleural effusion treated with videoassisted thoracoscopic talc pleurodesis. Interact Cardiovasc Thorac Surg 2006;5:307-10.

18. Vansteenkiste JF, Cho BC, Vanakesa T, et al. Efficacy of the MAGE-A3 cancer immunotherapeutic as adjuvant therapy in patients with resected MAGE-A3-positive nonsmall-cell lung cancer (MAGRIT): a randomised, doubleblind, placebo-controlled, phase 3 trial. Lancet Oncol 2016;17:822-35.

19. Cho BC, DE Pas T, Kalofonos H, et al. Prognostic Factors in Early-stage NSCLC: Analysis of the Placebo Group in the MAGRIT Study. Anticancer Res 2019;39:1403-9.
Cite this article as: Laisaar T. Thoracic surgery in Estonia. J Thorac Dis 2022;14(5):1719-1724. doi: 10.21037/jtd-21-1146 